\title{
Estrogen induces IDO expression via TGF- $\beta$ in chorionic villi and decidua during early stages of pregnancy
}

\author{
JUN WANG $^{1,2^{*}}$, ZHUO CHEN $^{1 *}$, ZIWEN XIAO $^{3}$, YUHONG WENG $^{3}$, \\ MINYAN YANG ${ }^{1}$, LIPING YANG ${ }^{2}$, YUANYUAN TU ${ }^{1}$, HUA ZHOU $^{1}$, LINGFEI WU $^{4}$, \\ FA SHUN ${ }^{5}$, PEIFAN LI ${ }^{6}$, GUANYOU HUANG ${ }^{1}$ and SHUYUN ZHAO ${ }^{1}$ \\ ${ }^{1}$ Department of Obstetrics and Gynecology, Reproductive Medicine Center, The Affiliated Hospital of \\ Guizhou Medical University; ${ }^{2}$ Department of Obstetrics and Gynecology, Guizhou Medical University; \\ ${ }^{3}$ Department of Obstetrics and Gynecology, The Affiliated Hospital of Guizhou Medical University, \\ Guiyang, Guizhou 550004; ${ }^{4}$ Department of Gastroenterology, Second Affiliated Hospital, Shantou University \\ Medical College, Shantou, Guangdong 515041; Departments of ${ }^{5}$ Urinary Surgery and ${ }^{6}$ Psychology, \\ The Affiliated Hospital of Guizhou Medical University, Guiyang, Guizhou 550004, P.R. China
}

Received September 19, 2019; Accepted April 30, 2020

DOI: $10.3892 / \mathrm{ijmm} .2020 .4658$

\begin{abstract}
Indoleamine 2,3-dioxygenase (IDO) is one of the most important proteins protecting the embryos from the mother's immune system during pregnancy; however, little is known about the regulation of expression of this protein at the maternal-fetal interface. In the current study, chorionic villi and decidua were collected from women at early stages of pregnancy. Samples of chorionic villi and decidua were cultured in medium containing different concentrations of $17 \beta$-estradiol and estriol respectively, with or without fulvestrant. Western blot analysis and/or immunofluorescent staining were used to detect the expression of transforming growth factor $\beta$ (TGF- $\beta$ ) and IDO in chorionic villi and decidua tissues. Both TGF- $\beta$ and IDO were expressed in chorionic villi and decidua. The expression levels of these two proteins increased the most in samples of chorionic villi and decidua cultured in medium containing $17 \beta$-estradiol at the concentration of $10 \mathrm{ng} / \mathrm{ml}$, or estriol at the concentration of $1 \mu \mathrm{g} / \mathrm{ml}$. This increase could be reversed when fulvestrant was
\end{abstract}

Correspondence to: Professor Shuyun Zhao, Department of Obstetrics and Gynecology, Reproductive Medicine Center, The Affiliated Hospital of Guizhou Medical University, 28 Guiyi Street, Guiyang, Guizhou 550004, P.R. China

E-mail: zhaoshuyunsci@126.com

*Contributed equally

Abbreviations: E1, estrone; E2, 17 $\beta$-estradiol; E3, estriol; IDO, indoleamine 2,3-dioxygenase; IFN- $\gamma$, interferon- $\gamma$; pDC, plasmacytoid dendritic cell; Th, T helper; TGF- $\beta$, transforming growth factor- $\beta$; Tregs, regulatory $\mathrm{T}$ cells

Key words: estrogen, indoleamine 2,3-dioxygenase, transforming growth factor- $\beta$, pregnancy, chorionic villi, decidua added in the medium at the concentration of $10 \mu \mathrm{g} / \mathrm{ml}$. IDO expression increased in a dose-dependent manner in tissue samples cultured in medium containing TGF- $\beta$. The results of the current study revealed that administration of estrogen at doses similar to those observed in healthy pregnant women may upregulate the expression of IDO by TGF- $\beta$, suggesting that estrogen may prevent allogeneic fetal rejection and may be used as an immunomodulator.

\section{Introduction}

Although a fetus attains only half of its genetic material from the mother, maternal-fetal tolerance allows implantation of the fetus within the womb and the establishment of a temporary immune system during fetal development $(1,2)$. The underlying molecular mechanism remains unclear; however, three hypotheses of maternal immunological tolerance have been proposed: i) Physical separation of fetal and maternal tissues; ii) antigenic immaturity of fetal tissues; and iii) immunological inertness (tolerance) of maternal tissues towards fetal alloantigens (3). However, these hypotheses do not fully explain the underlying mechanisms. It has been hypothesized trophoblast cells from the outer layer of a blastocyst act as an interface layer and provide nutrients and a constant blood supply to the embryo. Furthermore, trophoblast cells develop to form an important part of the placenta, particularly through their interactions with decidua and placental villi (4).

Estrogen is vital for the female reproductive development and the three major naturally occurring forms are: Estrone (E1), $17 \beta$-Estradiol (E2), Estriol (E3). During pregnancy, E2 and E3 serum levels have been reported to increase 100 and 1,000 times, respectively, while estrogen markedly decreases the levels of regulatory T-cells (Tregs) following parturition (5). During pregnancy, placenta cells produce E3. Estrogen also has a function in the immune system; however, its underlying molecular mechanism remains to be fully understood. 
Indoleamine 2,3-dioxygenase (IDO) is an essential enzyme in tryptophan catabolism. It degrades amino acid L-tryptophan into kynurenine, which depletes tryptophan and subsequently suppresses T-cell activity $(6,7)$. The molecular mechanisms protecting the fetus include trophoblast cells, major histocompatibility complex, T cell apoptosis, suppression of cell proliferation and IDO-mediated tryptophan catabolism (8). It has been demonstrated that IDO is expressed by human trophoblasts and decidual cells, and is activated at the maternal-fetal interface (9-11). Toxic effects of tryptophan metabolites are responsible for inhibition of $\mathrm{T}$ cell proliferation and Tregs, and it has been suggested that IDO may be associated with the $\mathrm{T}$ helper $(\mathrm{Th}) 1 / \mathrm{Th} 2$ cell balance $(6,12,13)$. Both direct and indirect analyses have reported that IDO is associated with human maternal fetal interface and the immune system $(14,15)$.

Transforming growth factor $\beta$ (TGF- $\beta$ ) is a multifunctional signal transducer, which is associated with cell apoptosis, cell cycle and differentiation, and has also been implicated in tumor growth (16). A previous study reported that IDO expression increased in mouse plasmacytoid dendritic cells (pDCs) treated with TGF- $\beta$ (17). Furthermore, in chorionic villi and decidua tissues of healthy pregnant women, both TGF- $\beta$ and IDO are expressed at high levels and TGF- $\beta$ expression is positively correlated with IDO expression (11). Thus, the current study hypothesized that TGF- $\beta$ may upregulate IDO expression, and that increased levels of estrogen may induce IDO expression in chorionic villi and decidual tissues by upregulating TGF- $\beta$ expression in pregnant women.

\section{Materials and methods}

Participants and samples. A total of 40 healthy pregnant women who underwent legal termination of pregnancy at the Affiliated Hospital of Guizhou Medical University (Guiyang, China) between April 2015 and October 2017 were recruited in the present study. The mean age of participants was $27.56 \pm 6.27$ years, while gestational age was $57.23 \pm 7.42$ days. All participants presented with normal embryonic development determined by ultrasonic examination, cases with abnormalities of the reproductive system were identified and excluded (18). The exclusion criteria were as follows: Participant with history of endometriosis, and chronic diseases associated with chronic hypertension, kidney disease and diabetes. The development of a healthy fetus was confirmed via ultrasonic examination, with no detectable uterine abnormality. All participants provided voluntary consent to pregnancy termination.

Tissue culture. Decidua and chorionic villi tissues were identified by morphology. Chorionic villi and decidua tissue samples collected under aseptic conditions were immediately placed in 0.1 M sterile PBS ( $\mathrm{pH} 7.2$ ), transferred to ice within $10 \mathrm{~min}$ and subsequently washed twice with PBS. Tissue samples were either preserved at $-80^{\circ} \mathrm{C}$ prior to western blot analysis or cut into small pieces ( $\leq 1 \mathrm{mg}$ wet weight) for tissue culture. The samples prepared for tissue culture were processed within 40 min of collection. The chorionic villi and decidua pieces were washed twice with F-12 nutrient mixture (F-12)/DMEM (Invitrogen; Thermo Fisher Scientific, Inc.), centrifuged at $1,200 \mathrm{x}$ g for $5 \mathrm{~min}$ at room temperature within less than $40 \mathrm{~min}$, and cultured in F-12/DMED supplemented with $10 \%$ FBS (Gibco, Thermo Fisher Scientific, Inc) and 1\% penicillin-streptomycin (Invitrogen; Thermo Fisher Scientific, Inc.) in a $\mathrm{CO}_{2}$ incubator (Thermo Fisher Scientific, Inc.) at $37^{\circ} \mathrm{C}$ with $5 \% \mathrm{CO}_{2}$.

Treatment of villi and decidua. Villi and decidua cultures were plated in six-well plates at a density of $5 \times 10^{5}$ cells/well (Corning Inc.) and cultured in phenol red-free DMED/Ham's F-12 (Gibco; Thermo Fisher Scientific, Inc.) supplemented with 10\% FBS (Gibco; Thermo Fisher Scientific, Inc.) and 1\% penicillin-streptomycin (Invitrogen; Thermo Fisher Scientific, Inc.) at $37^{\circ} \mathrm{C}$ with $5 \% \mathrm{CO}_{2}$. Villi and decidua cells were prepared for immunofluorescence (IF) and a part of western blotting experiments. TGF- $\beta 1$ powder (R\&D Systems, Inc.) was dissolved in PBS at three concentrations $(0.01,0.5$ and $0.1 \mathrm{ng} / \mathrm{ml}$, respectively) and incubated with the chorionic villi and decidua tissue sections for $48 \mathrm{~h}$ at $37^{\circ} \mathrm{C}$ with $5 \% \mathrm{CO}_{2}$. Fulvestrant was purchased from Selleck Chemicals, diluted in DMED/Ham's F-12 and stored at $4^{\circ} \mathrm{C}$. E2 and E3 were diluted in ethyl alcohol (all Sigma-Aldrich; Merck KGaA). An equal concentration of ethyl alcohol alone was used in the control group. Sections of chorionic villi or decidua were incubated in medium containing $10 \mathrm{ng} / \mathrm{ml} \mathrm{E} 2$ or $1 \mu \mathrm{g} / \mathrm{ml} \mathrm{E} 3$, prior to addition of $0.1,1$ and $10 \mu \mathrm{g} / \mathrm{ml}$ fulvestrant for $12 \mathrm{~h}$ at $37^{\circ} \mathrm{C}$ with $5 \% \mathrm{CO}_{2}$.

IF staining. For immunofluorescence staining, villi and decidua cells were treated with $10 \mathrm{mg} / \mathrm{ml} \mathrm{E} 2,1 \mu \mathrm{g} / \mathrm{ml} \mathrm{E} 3$ or $1 \mu \mathrm{g} / \mathrm{ml}$ fulvestrant for $48 \mathrm{~h}$, then fixed in PBS supplemented with $4 \%$ paraformaldehyde (Sigma-Aldrich; Merck KGaA) for $15 \mathrm{~min}$, prior to treatment in PBS supplemented with $0.5 \%$ Triton X-100 for 15 min. Cells were incubated with PBS containing $4 \%$ bovine serum albumin (Gibco; Thermo Fisher Scientific, Inc.) at room temperature for $30 \mathrm{~min}$ and subsequently washed three times with PBS ( $5 \mathrm{~min} /$ wash) Tissue samples were incubated with the following primary antibodies: IDO rabbit anti-human (1:1,000; cat. no. 86630; Cell Signaling Technology, Inc.) and TGF- $\beta$ rabbit anti human (1:500; cat. no. 3709; Cell Signaling Technology, Inc.) overnight at $4^{\circ} \mathrm{C}$. Following the primary antibody incubation, membranes were incubated with isothiocyanate-conjugated donkey anti-rabbit FITC (1:1,000; F8070; Beijing Solarbio Science \& Technology Co., Ltd.) and $\mathrm{Cy}^{\circledR} 3$ Immunoglobulin $\mathrm{G}$ donkey anti-rabbit (1:1,000; S1050; Beijing Solarbio Science \& Technology Co., Ltd.) secondary antibodies for $1 \mathrm{~h}$ at room temperature. All antigen were retrieval Once store at $4{ }^{\circ} \mathrm{C}$, staining cells were wash with PBS reagent 3 times every 5 mins. Nuclei were stained with DAPI (cat. no. D1306; Invitrogen; Thermo Fisher Scientific, Inc.) for $3 \mathrm{~min}$ at room temperature, mounted onto slides and confocal dishes, and observed under a confocal microscope (LSM 710; Carl Zeiss AG). Images were captured using a $63 \mathrm{X}$ numerical aperture objective.

Western blotting. Western blot analysis was performed as previously described (10). Briefly, total protein was extracted from chorionic villi tissues, decidua tissues or cultured isolated cells using ice-cold RIPA (Sigma-Aldrich; Merck KGaA). Tissue samples or isolated cells were treated with 
protease inhibitors at $4^{\circ} \mathrm{C}$ for $30 \mathrm{~min}$ (Sigma Aldrich) and proteins were isolated followed by centrifugation at $11,000 \mathrm{xg}$ for $20 \mathrm{~min}$ at $4^{\circ} \mathrm{C}$ (repeated twice). Proteins were separated via SDS-PAGE on 10 or $15 \%$ gel. The separated proteins were subsequently transferred onto PVDF membranes (PerkinElmer, Inc.) at $200 \mathrm{~mA}$ for $1.5 \mathrm{~h}$. After blocking for $1 \mathrm{~h}$ in 5\% non-fat milk, the membranes were incubated with the following primary antibodies: Anti-human IDO monoclonal antibody (1:3,000; cat. no. 86630; Cell Signaling Technology, Inc.), TGF- $\beta$ polyclonal antibody (1:3,000; cat. no. 3709; Cell Signaling Technology, Inc.), or human GAPDH polyclonal antibody (1:6,000; cat. no. GTX100118; GeneTex, Inc.) for $3 \mathrm{~h}$ at room temperature. Membranes were washed three time with tris-buffered saline with Tween-20. Following the primary antibody incubation, membranes were incubated with horseradish peroxidase-labeled donkey anti-rabbit immunoglobulin G antibody (Cell Signaling Technology, Inc.) for $1 \mathrm{~h}$ at room temperature. Protein bands were visualized using the ECL kit (PerkinElmer, Inc.) followed by autoradiography (GenoSwns1880, 3300018-7Q; Clinx Science Instruments Co. Ltd.). All experiment were performed in triplicate.

Statistical analysis. All statistical analyses were performed using GraphPad (version 6.0; GraphPad Software, Inc.) and SPSS (23.0; IBM, Corp.) and presented as the mean \pm standard error of the mean. Two independent groups were compared using Pearson's correlation analysis. One-way ANOVA followed by Student-Newman-Keuls post hoc test or Turkey's test were used to assess protein expression following western blot analysis. $\mathrm{P}<0.05$ was considered to indicate a statistically significant difference.

\section{Results}

IDO and TGF- $\beta$ expression in chorionic villi and decidua tissues at early stages of pregnancy. The western blot analysis demonstrated that IDO (Fig. 1A) and TGF- $\beta$ (Fig. 1B) were expressed in both villi and decidua tissue samples. IF staining indicated that TGF- $\beta$ was predominantly expressed in the cytoplasm of villi and decidua cells as indicated by red fluorescence, while IDO was identified in both the cytoplasm and nucleus of villi and decidua cells as indicated by green fluorescence (Fig. 1C and D). Furthermore, villi and decidua cells exhibited a similar cell size and IDO and TGF- $\beta$ expression levels.

E2 and E3 induce IDO expression in chorionic villi and decidua. In order to confirm whether estrogen affected IDO expression, the chorionic villi and decidua sections were cultured in the medium containing 100,10 or $1 \mathrm{ng} / \mathrm{ml} \mathrm{E} 2$ or 10 , 1 and $0.1 \mu \mathrm{g} / \mathrm{mlE} 3$ for $48 \mathrm{~h}$. Western blot analysis demonstrated that IDO expression increased in chorionic villi (Fig. 2A, $\mathrm{C}, \mathrm{E}$ and $\mathrm{G}$ ) and decidua (Fig. 2B, D, F and H) cultured in the medium containing E2 (Fig. 2A-D) or E3 (Fig. 2E-H) compared with the control group. The greatest increase in IDO expression was detected in sections of chorionic villi and decidua cultured in the medium containing $10 \mathrm{ng} / \mathrm{ml}$ of E2 or in villi and decidua cultured in $1 \mu \mathrm{g} / \mathrm{ml}$ of E3.

E2 and E3 induce TGF- $\beta$ expression in chorionic villi and decidua. The effect of estrogen on TGF- $\beta$ expression was

\section{A Decidua Villi}

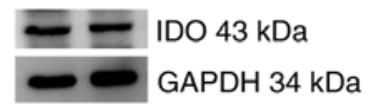

B Decidua Villi
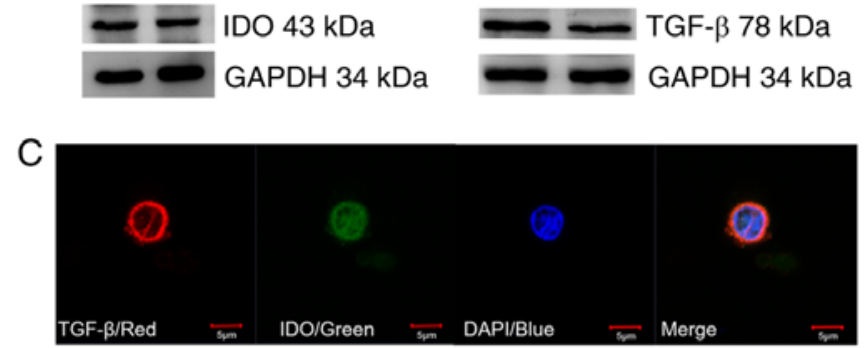

Chorionic villi

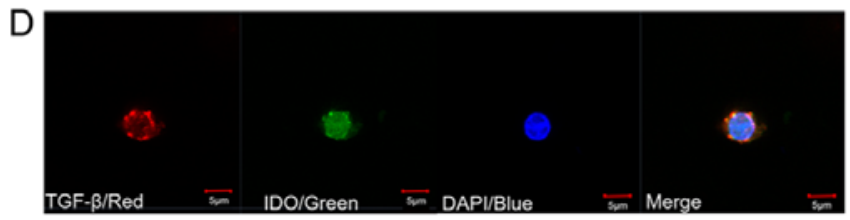

Decidua

Figure 1. Expression of IDO and TGF- $\beta$ in chorionic villi and decidua. The expression of (A) IDO and (B) TGF- $\beta$ in chorionic villi and decidua detected by western blot analysis. Data are representative of three independent experiments. The expression of IDO (green fluorescence) and TGF- $\beta$ (red fluorescence) detected by immunofluorescence staining in (C) chorionic villi and (D) decidua cells. Cell nuclei were stained by DAPI (blue fluorescence). Data are representative of three independent experiments. Magnification, $x 63$. IDO, indoleamine 2,3-dioxygenase; TGF- $\beta$, transforming growth factor $\beta$.

determined in the chorionic villi and decidua sections. Western blot analysis illustrated that TGF- $\beta$ expression increased in chorionic villi and decidua tissues cultured in the medium containing $10 \mathrm{ng} / \mathrm{ml} \mathrm{E} 2$ (Fig. 2I) or $1 \mu \mathrm{g} / \mathrm{ml} \mathrm{E} 3$ (Fig. 2J) compared with control group.

E2 and E3 induce IDO expression via TGF- $\beta$ in chorionic villi and decidua. To elucidate the underlying molecular mechanism by which estrogen induces IDO expression, chorionic villi and decidua cells were incubated in medium containing 100,10 and $1 \mathrm{ng} / \mathrm{ml} \mathrm{E} 2$ or 10,1 and $0.1 \mu \mathrm{g} / \mathrm{ml} \mathrm{E} 3$ for $48 \mathrm{~h}$. Western blot analysis indicated that both IDO and TGF- $\beta$ expression levels increased in $10 \mathrm{ng} / \mathrm{ml}$ of E2 and $1 \mu \mathrm{g} / \mathrm{ml}$ of E3 groups compared with the other treatment concentrations, and that TGF- $\beta$ expression was positively associated with IDO levels in sections of chorionic villi (Fig. 3C and E; $\mathrm{R}=0.736$ and 0.756 ) and decidua (Fig. $3 \mathrm{H}$ and $\mathrm{J} ; \mathrm{R}=0.567$ and 0.714 ) cultured in the medium containing E2 (Fig. B-C) or E3 (Fig. D-E). The greatest increase in IDO and TGF- $\beta$ expression levels was observed in sections of chorionic villi (Fig. 3A, B and D) and decidua (Fig. 3F, G and I) cultured in the medium containing $10 \mathrm{ng} / \mathrm{ml} \mathrm{E} 2$ (Fig. 3A, B, F and G) or $1 \mu \mathrm{g} / \mathrm{ml} \mathrm{E3} \mathrm{(Fig.} \mathrm{3A,} \mathrm{D,} \mathrm{F} \mathrm{and} \mathrm{I).} \mathrm{The} \mathrm{results} \mathrm{demonstrated}$ that the TGF- $\beta$ expression was positively associated with IDO expression in cultured chorionic villi and decidua in the presence of estrogen, suggesting that estrogen may simultaneously upregulate TGF- $\beta$ and IDO expression.

In order to determine whether TGF- $\beta$ induced the expression of IDO, sections of chorionic villi and decidua were incubated in the medium containing $0.01,0.5$ and $0.1 \mathrm{ng} / \mathrm{ml}$ TGF- $\beta$ for $48 \mathrm{~h}$. Western blot analysis demonstrated that IDO expression increased in a dose-dependent manner in both chorionic villi (Fig. 3K and M) and decidua (Fig. 3L and N) cultured in the medium containing TGF- $\beta$. Taken together, 
A $100 \mathrm{ng} / \mathrm{ml} \quad 10 \mathrm{ng} / \mathrm{ml} \quad 1 \mathrm{ng} / \mathrm{ml} \quad$ Control

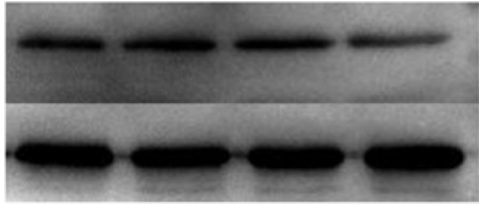

Chorionic villi treated with E2

C

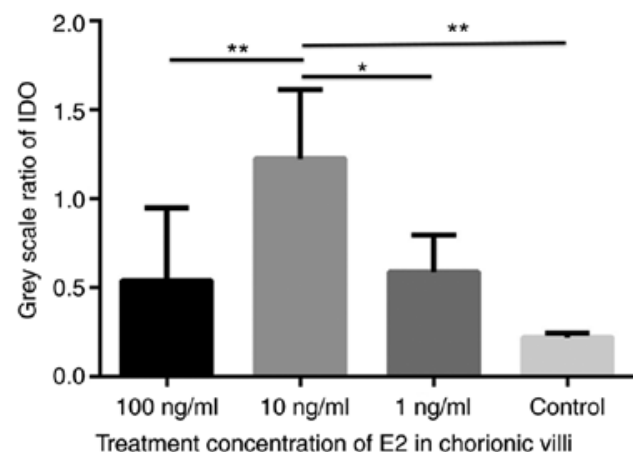

E

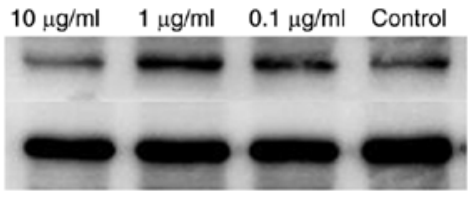

Chorionic villi treated with E3

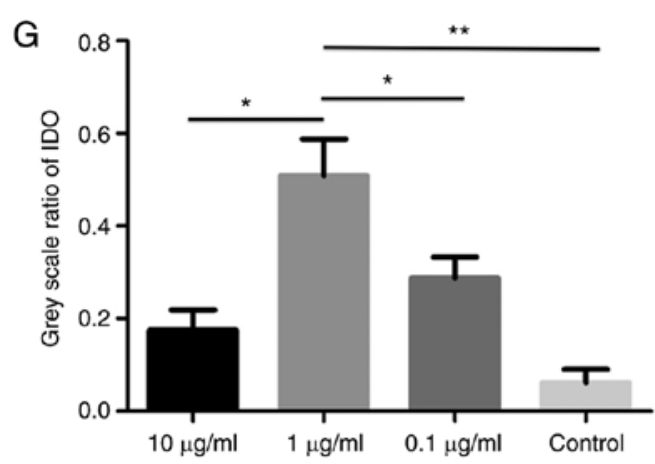

Treatment concentration of E3 in chorionic villi

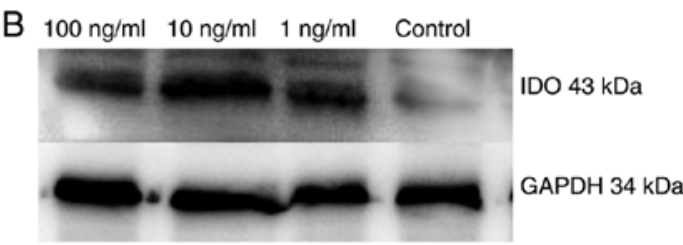

Decidua treated with E2

D
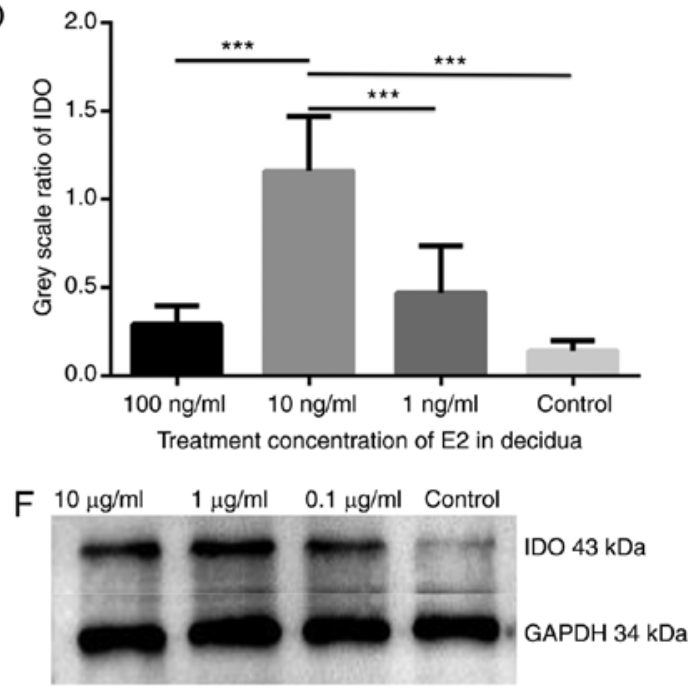

Decidua treated with E3

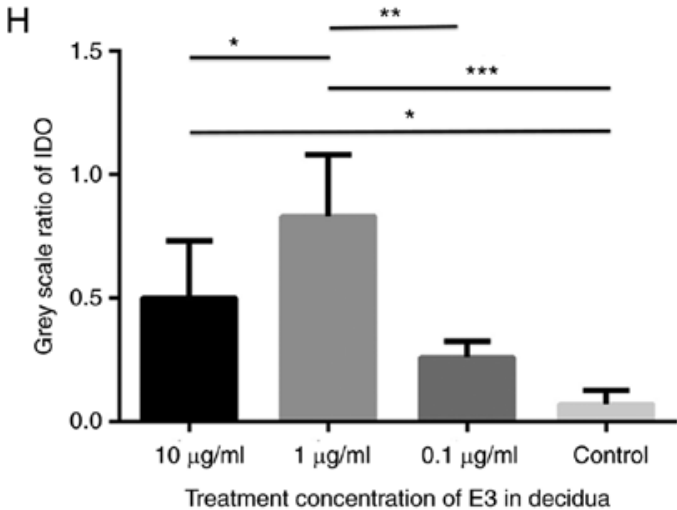

। D $\mathrm{V}$

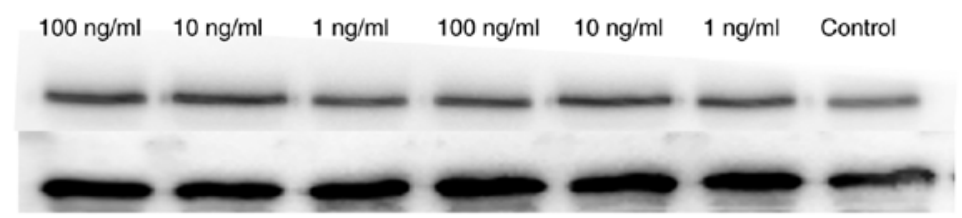

TGF- $\beta 78$ kDa

Chorionic villi and decidua treated with E2

J

$\mathrm{D}$

$\mathrm{V}$

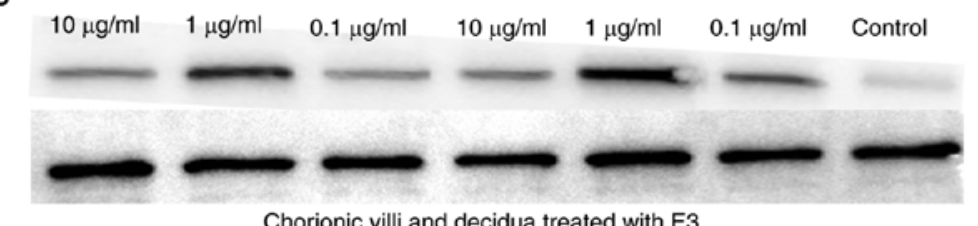

TGF- $\beta 78 \mathrm{kDa}$

GAPDH $34 \mathrm{kDa}$

Chorionic villi and decidua treated with $\mathrm{E} 3$

Figure 2. E2 and E3 induce IDO and TGF- $\beta$ expression in chorionic villi and decidua, as detected by western blot analysis. Western blots presenting the expression of IDO in (A) chorionic villi and (B) decidua treated with different concentrations of E2. Semi-quantitative analysis of IDO expression in (C) chorionic villi and (D) decidua treated with E2. Western blots presenting the expression of IDO in (E) chorionic villi and (F) decidua treated with different concentrations of E3. Semi-quantitative analysis IDO expression in (G) chorionic villi and $(\mathrm{H})$ decidua treated with E3. TGF- $\beta$ expression in chorionic villi and decidua cultured in the medium containing (I) E2 or (J) E3. Data are presented as the mean \pm SE and representative of three independent experiments. Grey scale ratio was calculated using the GAPDH band. ${ }^{*} \mathrm{P}<0.05,{ }^{* *} \mathrm{P}<0.01$ and ${ }^{* * * *} \mathrm{P}<0.001$. IDO, indoleamine 2,3-dioxygense; E2, 17 $\beta$-estradiol; E3, estriol; TGF- $\beta$, transforming growth factor $\beta$; $\mathrm{V}$, chorionic villi; $\mathrm{D}$, decidua. 
A

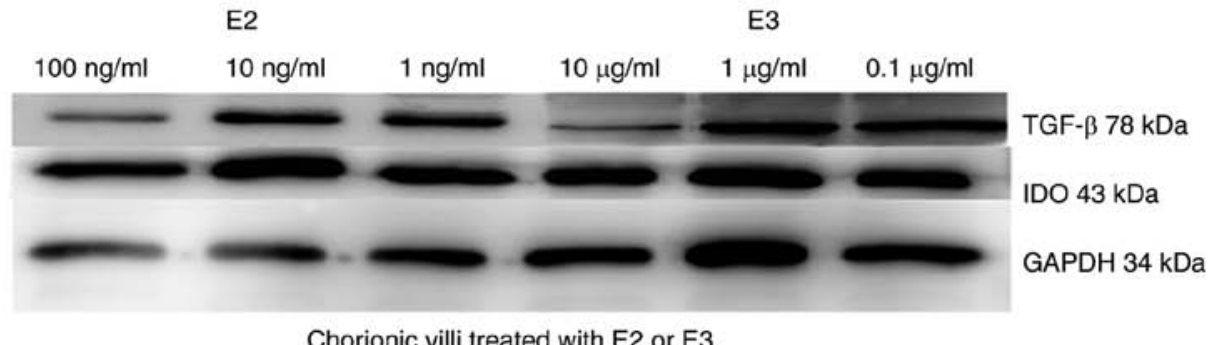

B
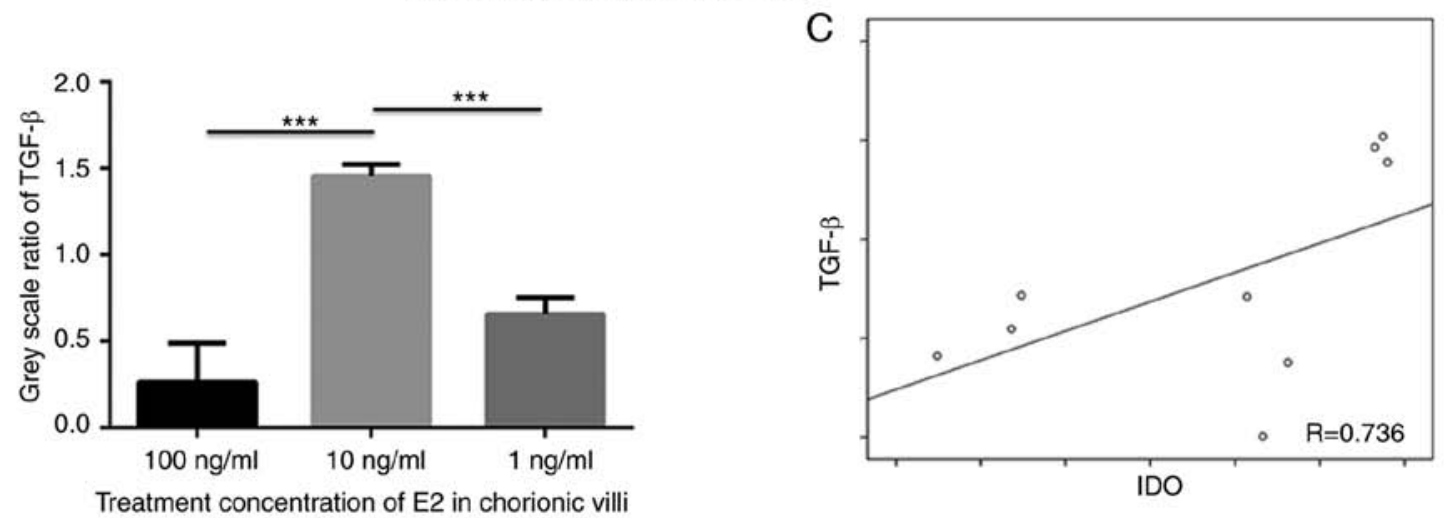

D

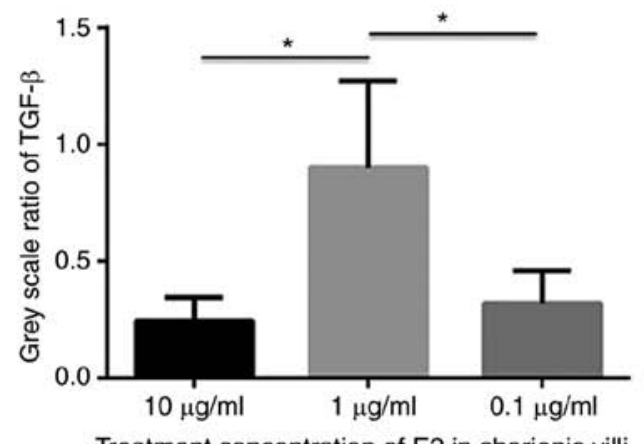

E

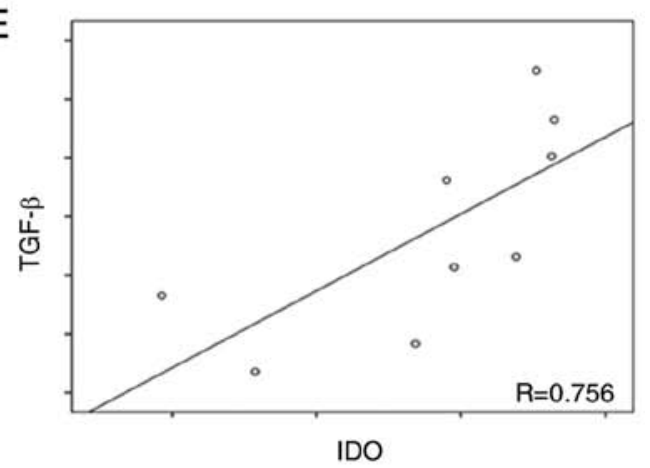

$\mathrm{F}$

$\begin{array}{llllll} & \mathrm{E} 2 & & & \mathrm{E} 3 \\ \mathrm{ng} / \mathrm{ml} & 10 \mathrm{ng} / \mathrm{ml} & 1 \mathrm{ng} / \mathrm{ml} & 10 \mu \mathrm{g} / \mathrm{ml} & 1 \mu \mathrm{g} / \mathrm{ml} & 0.1 \mu \mathrm{g} / \mathrm{ml}\end{array}$

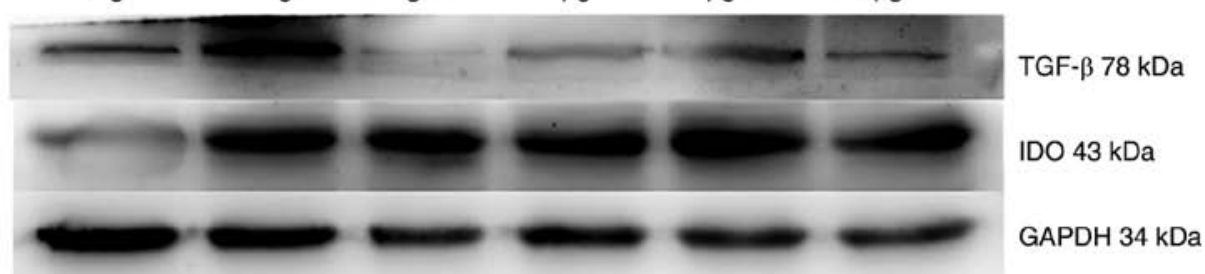

Decidua treated with E2 or E3
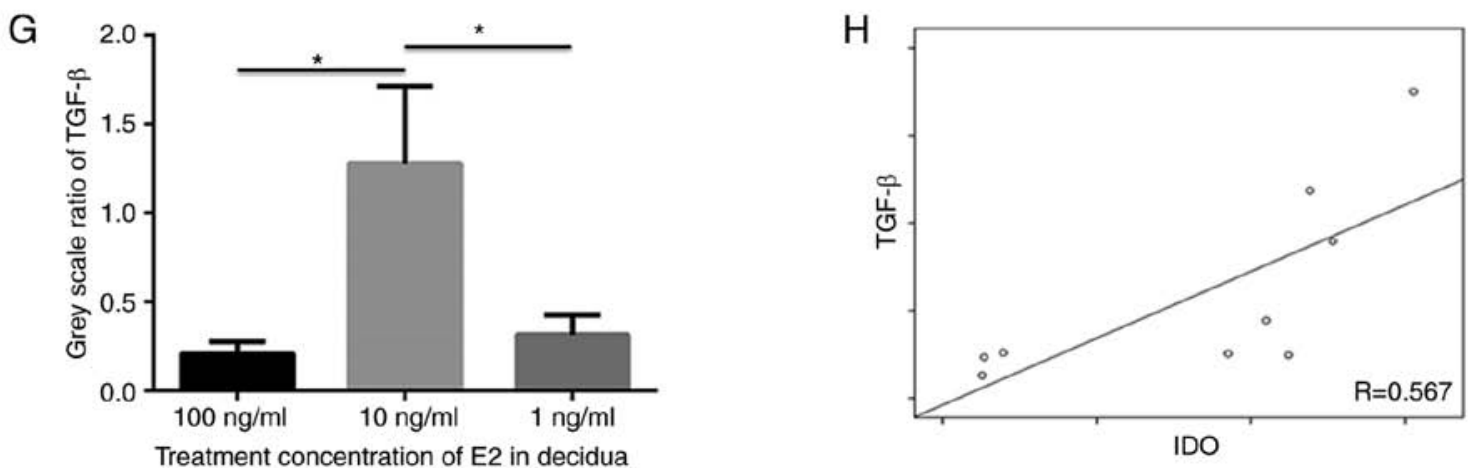

Figure 3. E2 and E3 induces IDO expression by TGF- $\beta$ in chorionic villi and decidua, as detected by western blot analysis. (A) Western blots presenting the expression of IDO and TGF- $\beta$ in chorionic villi following treatment with E2 or E3 for $48 \mathrm{~h}$. (B) Semi-quantitative analysis of TGF- $\beta$ levels in chorionic villi following treatment with E2. (C) Correlation between IDO and TGF- $\beta$ levels following treatment with E2 in chorionic villi. (D) Semi-quantitative analysis of TGF- $\beta$ levels in chorionic villi following treatment with E3. (E) Correlation between IDO and TGF- $\beta$ levels following treatment with E3 in chorionic villi. (F) Western blots presenting the expression of IDO and TGF- $\beta$ in decidua following treatment with E2 or E3 for 48 h. (G) Semi-quantitative analysis of TGF- $\beta$ levels in decidua following treatment with E2. (H) Correlation between IDO and TGF- $\beta$ levels following treatment with E2 in decidua. 

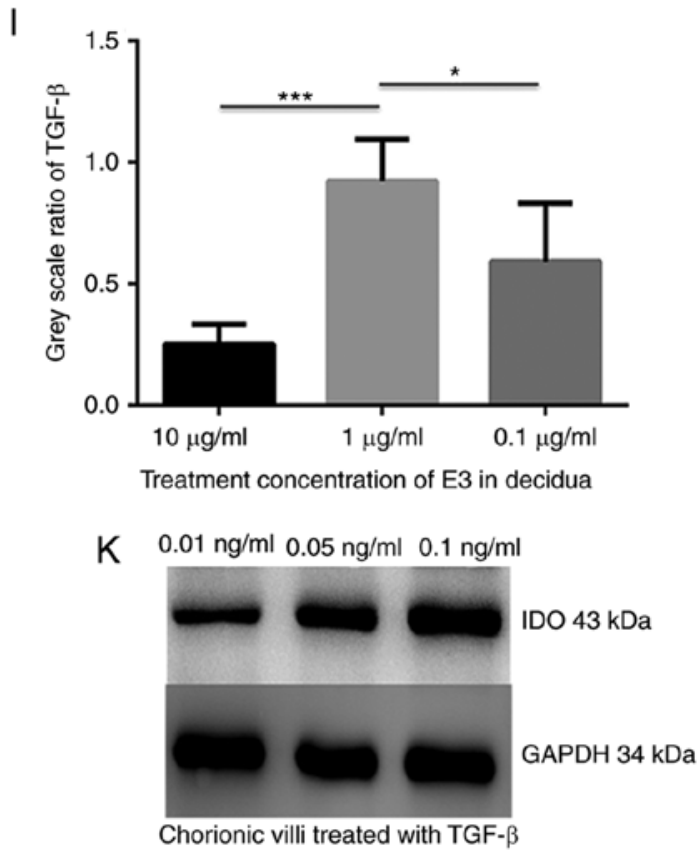

M

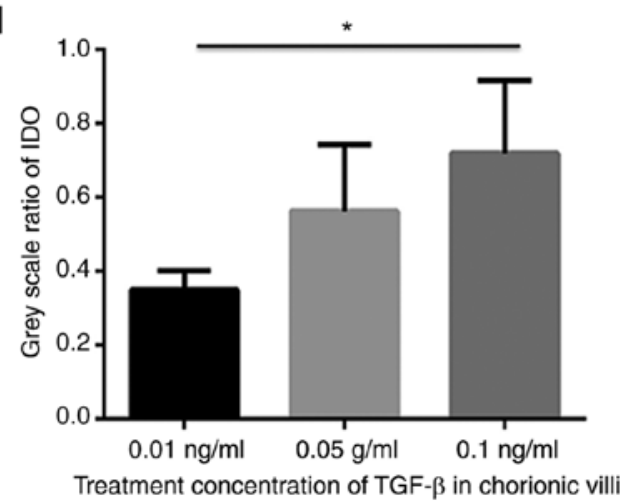

$J$

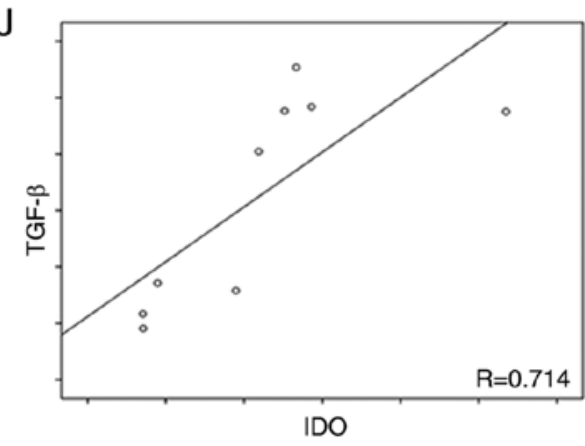

L $\quad 0.01 \mathrm{ng} / \mathrm{ml} 0.05 \mathrm{ng} / \mathrm{ml} 0.1 \mathrm{ng} / \mathrm{ml}$

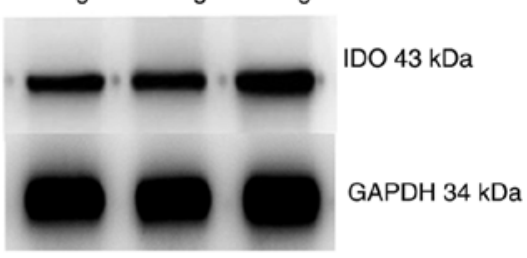

Decidua treated with TGF- $\beta$

$\mathrm{N}$

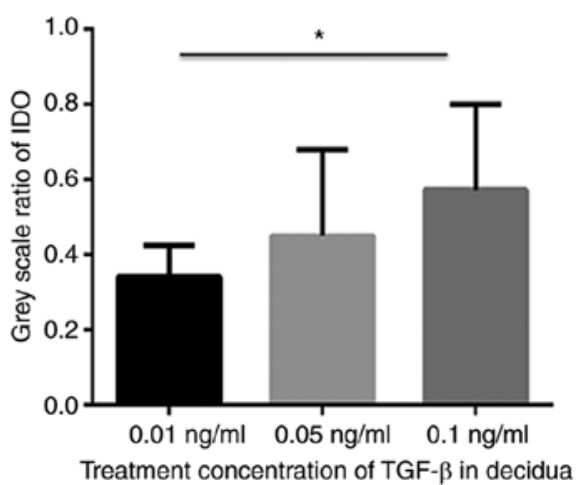

Figure 3. Continued. (I) Semi-quantitative analysis of TGF- $\beta$ levels in decidua following treatment with E3. (J) Correlation between IDO and TGF- $\beta$ levels following treatment with E3 in decidua. IDO expression in $(\mathrm{K})$ chorionic villi and $(\mathrm{L})$ decidua following treatment with different concentration of TGF- $\beta$. Semi-quantitative analysis of IDO expression levels in (M) chorionic villi and (N) decidua treated with different concentrations of TGF- $\beta$. Data are presented as the mean $\pm \mathrm{SE}$ and representative of three independent experiments. Grey scale ratio was calculated using the GAPDH band. ${ }^{*} \mathrm{P}<0.05$ and ${ }^{* * * *} \mathrm{P}<0.001$. IDO, indoleamine 2,3-dioxygenase; E2, 17 $\beta$-estradiol; E3, estriol; TGF- $\beta$, transforming growth factor $\beta$

these results suggest that TGF- $\beta$ may upregulate the expression of IDO and that estrogen may induce IDO expression via TGF- $\beta$.

Fulvestrant decreases estrogen-depended upregulation of IDO by inhibiting TGF- $\beta$ expression in chorionic villi and decidua. To validate whether estrogen induced IDO expression via TGF- $\beta$ in chorionic villi and decidua, chorionic villi or decidua cells were incubated in medium containing $10 \mathrm{ng} / \mathrm{ml} \mathrm{E} 2$ or $1 \mu \mathrm{g} / \mathrm{ml} \mathrm{E}$, prior to addition of $0.1,1$ and $10 \mu \mathrm{g} / \mathrm{ml}$ fulvestrant for $12 \mathrm{~h}$. Western blot analysis demonstrated that both IDO and TGF- $\beta$ expression decreased with the increased fulvestrant dosage in chorionic villi (Fig. 4A-H) and decidua (Fig. 5A-H), cultured in the medium containing $10 \mathrm{ng} / \mathrm{ml} \mathrm{E} 2$ and $0.1,1$ or $10 \mu \mathrm{g} / \mathrm{ml}$ fulvestrant (Figs. 4A and B, and 5A and B), $1 \mu \mathrm{g} / \mathrm{ml}$ E3 added with $0.1,1$ or $10 \mu \mathrm{g} / \mathrm{ml}$ fulvestrant (Figs. 4E and F, and $5 \mathrm{E}$ and F), respectively. For IF staining, chorionic villi or decidua were treated with $10 \mathrm{ng} / \mathrm{ml} \mathrm{E} 2$ (Figs. $4 \mathrm{C}$ and $5 \mathrm{C}$ ) or $10 \mathrm{ng} / \mathrm{ml} \mathrm{E} 2$ and $1 \mu \mathrm{g} / \mathrm{ml}$ fulvestrant (Figs. 4D and 5D), $1 \mu \mathrm{g} / \mathrm{ml} \mathrm{E3} \mathrm{(Figs.} \mathrm{4G} \mathrm{and} \mathrm{5G)} \mathrm{or}$
$1 \mu \mathrm{g} / \mathrm{ml} \mathrm{E} 3$ and $1 \mu \mathrm{g} / \mathrm{ml}$ fulvestrant (Figs. $4 \mathrm{H}$ and $5 \mathrm{H}$ ), respectively. The greatest decrease in IDO and TGF- $\beta$ expression was observed in sections of chorionic villi (Fig. 4A and E) and decidua (Fig. 5A and E) cultured in the medium containing $10 \mathrm{ng} / \mathrm{ml}$ of E2 and $10 \mu \mathrm{g} / \mathrm{ml}$ fulvestrant (Figs. 4A and 5A), or in medium containing $1 \mu \mathrm{g} / \mathrm{ml}$ of E3 and $10 \mu \mathrm{g} / \mathrm{ml}$ fulvestran (Figs. 4E and 5E). Overall, the results demonstrated that fulvestrant had the ability to decreased estrogen-depended upregulation of IDO, partly by inhibiting TGF- $\beta$ expression.

\section{Discussion}

IDO is considered the main protein that protects embryos from the maternal immune system. During pregnancy, IDO is secreted by placental syncytiotrophoblasts, cytotrophoblasts, decidual cells and maternal monocyte-macrophages, which inhibit the T-lymphocyte reaction and mediate the immune tolerance to the fetus via tryptophan depletion and defective tryptophan catabolism (19). Previous studies have predominantly focused on investigating IDO expression and 

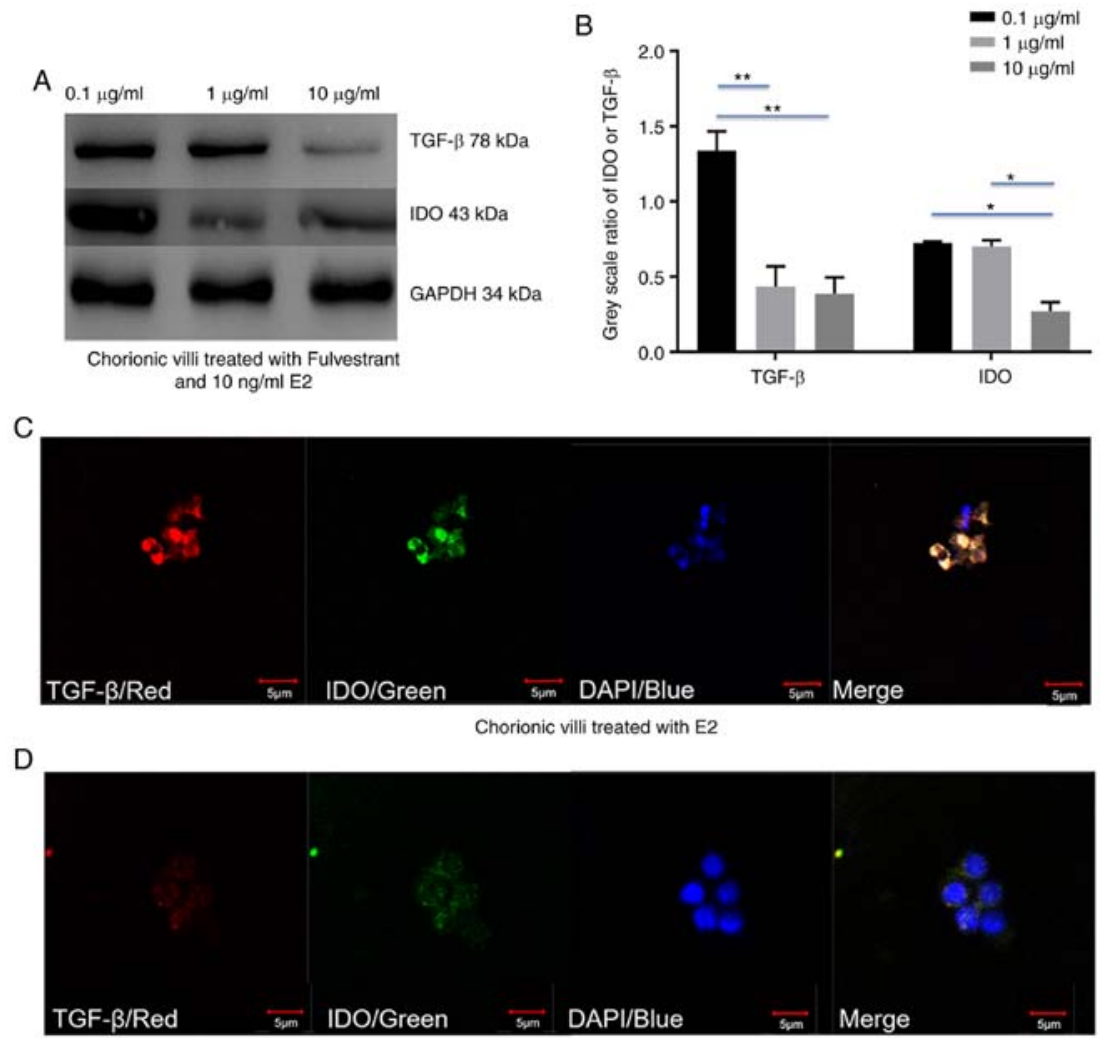

Chorionic villi treated with E2 and Fulvestrant

E

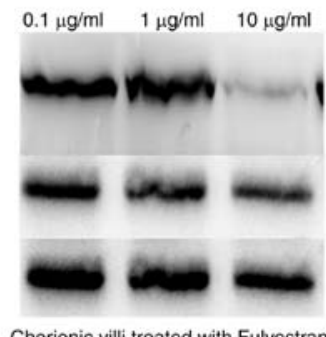

Chorionic villi treated with Fulvestrant and $1 \mu \mathrm{g} / \mathrm{ml} \mathrm{E} 3$

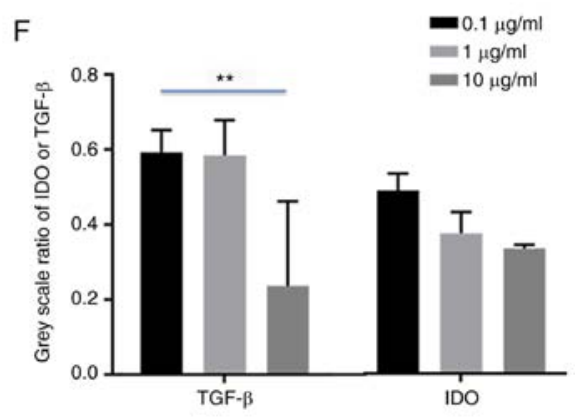

G

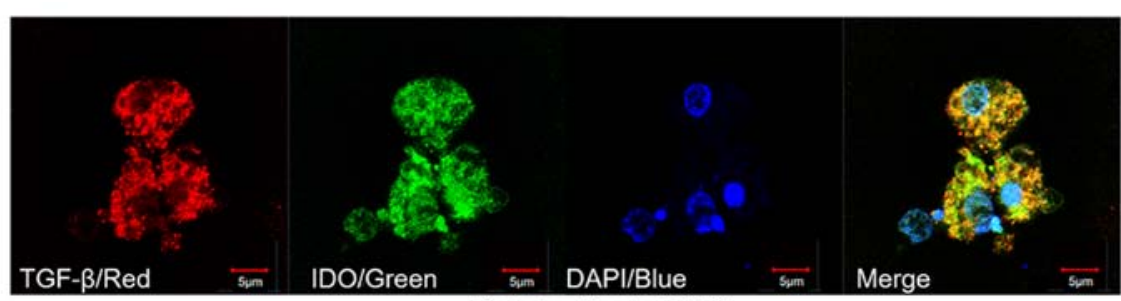

Chorionic villi treated with $\mathrm{E} 3$

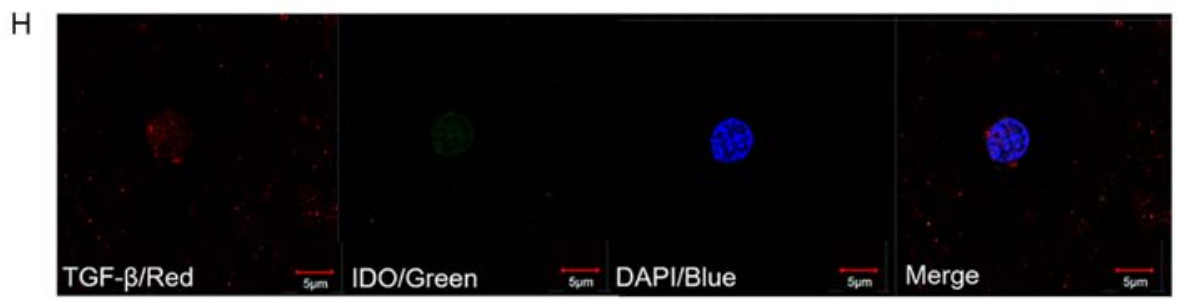

Chorionic villi treated with E3 and Fulvestrant

Figure 4. Fulvestrant inhibits estrogen-depended upregulation of IDO in chorionic villi. (A) Western blots presenting the expression of IDO and TGF- $\beta$ in chorionic villi following treatment with $10 \mathrm{ng} / \mathrm{ml} \mathrm{E} 2$ and $0.1,1$ and $10 \mu \mathrm{g} / \mathrm{ml}$ fulvestrant. (B) Semi-quantitative analysis of TGF- $\beta$ and IDO levels in chorionic villi following treatment with E2 and fulvestrant. Immunofluorescent staining of IDO and TGF- $\beta$ in cultured chorionic villi treated with (C) E2 only and (D) E2 and fulvestran. (E) Western blots presenting the expression of IDO and TGF- $\beta$ in chorionic villi following treatment with $1 \mu \mathrm{g} / \mathrm{ml} \mathrm{E} 3$ and $0.1,1$ and $10 \mu \mathrm{g} / \mathrm{ml}$ fulvestrant. (F) Semi-quantitative analysis of TGF- $\beta$ and IDO levels in chorionic villi following treatment with E3 and fulvestrant. Immunofluorescent staining of IDO and TGF- $\beta$ in cultured chorionic villi treated with (G) E3 only and (H) E3 and fulvestrant. Data are presented as the mean \pm SE and representative of three independent experiments. Grey scale ratio was calculated using the GAPDH band. The expression of IDO (green fluorescence) and TGF- $\beta$ (red fluorescence) was detected by immunofluorescence staining (magnification x63). Cell nuclei were stained by DAPI (blue fluorescence). ${ }^{*} \mathrm{P}<0.05$ and ${ }^{* * *} \mathrm{P}<0.01$. IDO, indoleamine 2,3-dioxygenase; E2, 17 $\beta$-estradiol; E3, estriol; TGF- $\beta$, transforming growth factor $\beta$. 


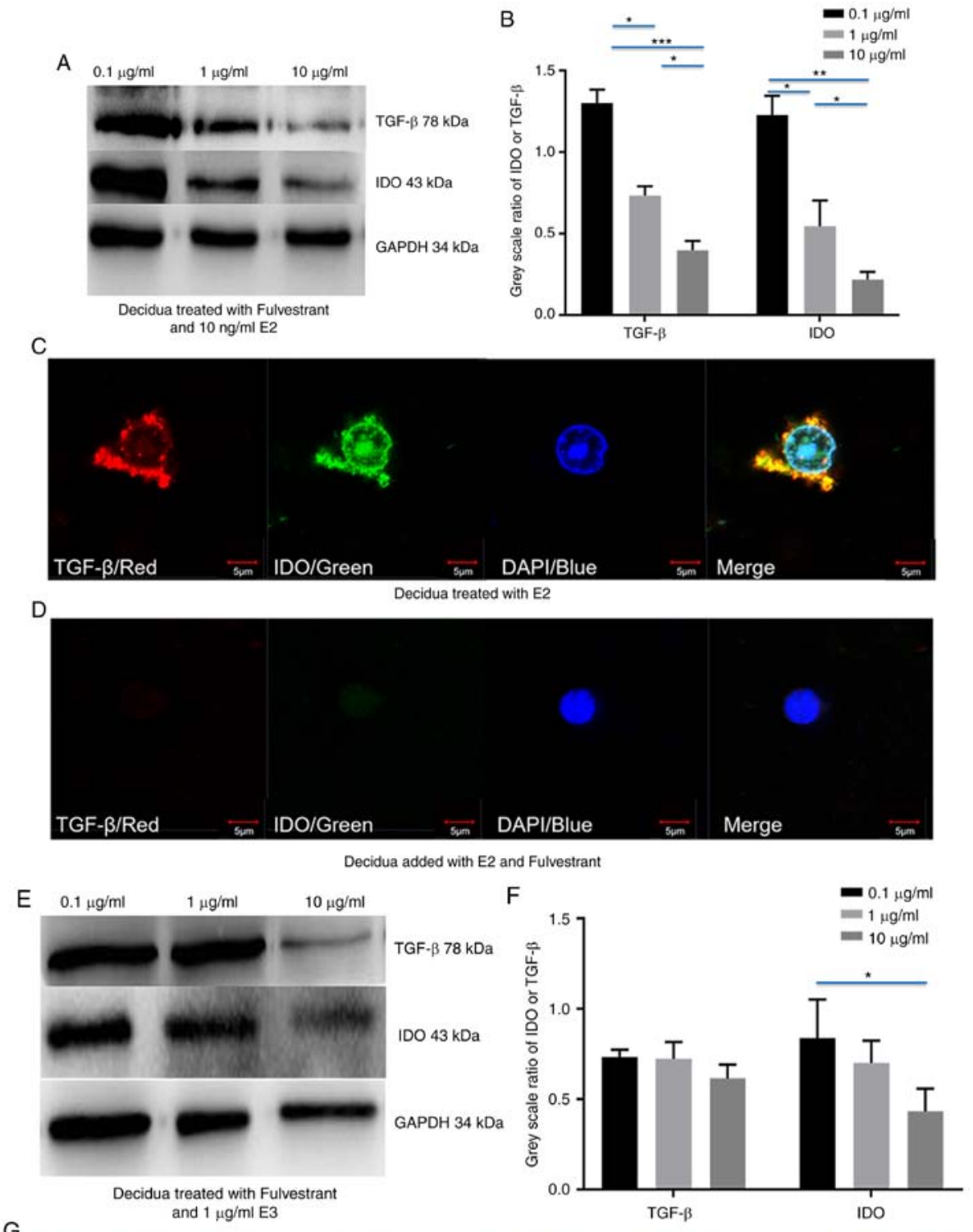

G and $1 \mu \mathrm{g} / \mathrm{ml} \mathrm{E} 3$
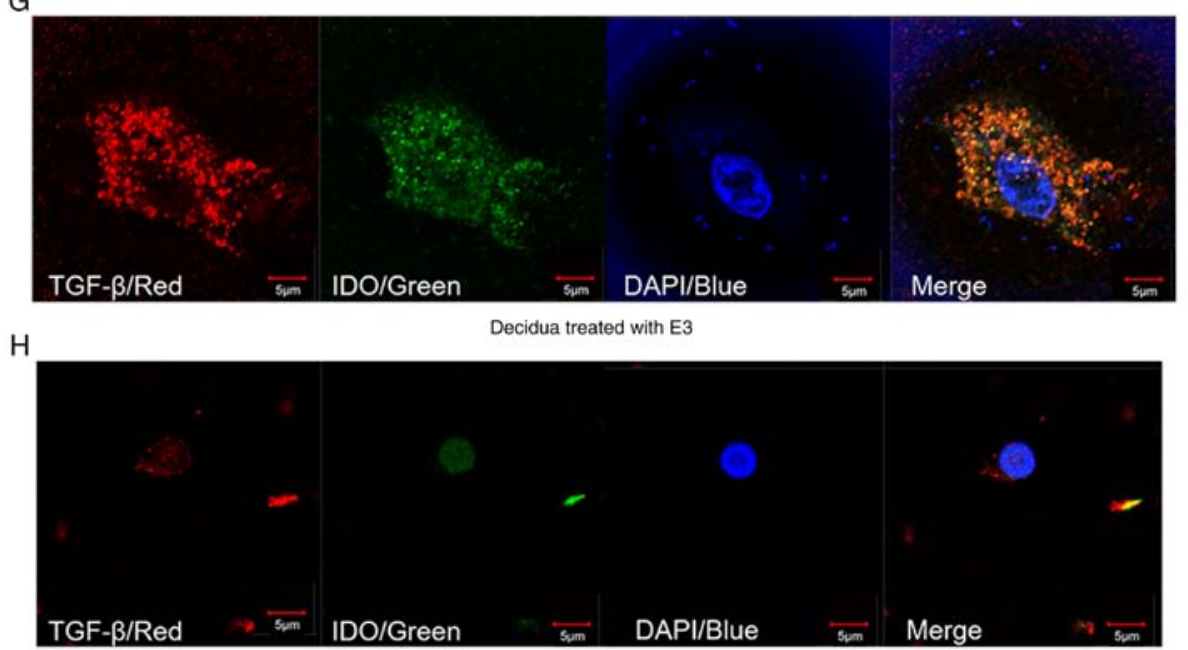

Decidua added with E3 and Fulvestran

Figure 5. Fulvestrant inhibits estrogen-depended upregulation of IDO in decidua. (A) Western blots presenting the expression of IDO and TGF- $\beta$ in decidua following treatment with $10 \mathrm{ng} / \mathrm{ml} \mathrm{E} 2$ and $0.1,1$ and $10 \mu \mathrm{g} / \mathrm{ml}$ fulvestrant. (B) Semi-quantitative analysis of TGF- $\beta$ and IDO levels in decidua following treatment with E2 and fulvestrant. Immunofluorescent staining of IDO and TGF- $\beta$ in cultured decidua treated with (C) E2 only and (D) E2 and fulvestran. (E) Western blots presenting the expression of IDO and TGF- $\beta$ in decidua following treatment with $1 \mu \mathrm{g} / \mathrm{ml} \mathrm{E} 3$ and $0.1,1$ and $10 \mu \mathrm{g} / \mathrm{ml}$ fulvestrant. (F) Semi-quantitative analysis of TGF- $\beta$ and IDO levels in decidua following treatment with E3 and fulvestrant. Immunofluorescent staining of IDO and TGF- $\beta$ in cultured decidua treated with (G) E3 only and (H) E3 and fulvestrant. Data are presented as the mean \pm SE and representative of three independent experiments. Grey scale ratio was calculated using the GAPDH band. The expression of IDO (green fluorescence) and TGF- $\beta$ (red fluorescence) was detected by immunofluorescence staining (magnification, x63). Cell nuclei were stained by DAPI (blue fluorescence). ${ }^{*} \mathrm{P}<0.05,{ }^{* *} \mathrm{P}<0.01$ and ${ }^{* * * *} \mathrm{P}<0.001$. IDO, indoleamine 2,3 -dioxygenase; E2, $17 \beta$-estradiol; E3, estriol; TGF- $\beta$, transforming growth factor $\beta$. 
function (20). It has been reported that interferon- $\gamma($ IFN- $\gamma)$ secreted by infiltrating leukocytes may increase IDO expression in endometrial stromal cells (21); however, little is known about the regulation of IDO expression at the maternal-fetal interface.

Estrogen affects the development of reproductive capabilities, and high E2 and E3 secretion levels have been observed during the gestation period. Estrogen-mediated IDO expression in monocyte-derived dendritic cells has been reported to limit T-cell proliferation and Th1/Th2 cytokine production in patients with multiple sclerosis (22). During pregnancy, the mean cord serum concentration of E2 is $\sim 7.5 \mathrm{ng} / \mathrm{ml}$ (range, 4-13 ng/ml) and the mean cord serum concentration of E3 is $0.3 \mu \mathrm{g} / \mathrm{ml}$ (range, $0.2-0.5 \mu \mathrm{g} / \mathrm{ml}$ ) (23). It has been reported that during pregnancy, estradiol may enhance the production of interleukin (IL)-10 and maintain Th2 cytokine expression (24). The results of the present study indicated that E2 and E3 may induce IDO expression, and demonstrated that IDO expression increased most notably when E2 and E3 were administered at concentrations similar to those normally observed in pregnant women. However, further studies are required to fully elucidate the molecular mechanism by which estrogen induces IDO expression at the maternal-fetal interface. The IDO expression induced by IFN- $\gamma$ may explain the immunoregulatory effects of this enzyme in acute inflammation; however, animal experiments indicated that long-term IDO expression in noninflammatory contexts is driven by TGF- $\beta$, as demonstrated in mouse pDCs treated with TGF- $\beta$ (17).

Our previous study demonstrated that TGF- $\beta$ expression was positively associated with IDO expression in chorionic villi and decidua tissues of healthy pregnant women (11). In the present study, IDO expression increased in chorionic villi and decidua cultured in the medium containing TGF- $\beta$. Thus, the current results support the hypothesis that TGF- $\beta$ may upregulate the expression of IDO in chorionic villi and decidua.

TGF- $\beta$ is closely associated with tissue remodeling events and reproductive processes, and is known to be abundantly expressed in the endometrium, decidua and chorionic villi. This protein is a vital regulator of endometrial and placental development and functions. TGF- $\beta$ affects several modulatory effects on endometrium, such as preparation events for implantation, interactions with preimplantation embryos, and promoting pre- and post-implantation embryo development. TGF- $\beta$ is also known to have several modulatory effects on trophoblast cells, such as inhibition of proliferation and invasiveness, and stimulation of differentiation by inducing multinucleated cell formation $(25,26)$

It has been reported that estrogen can upregulate TGF- $\beta$ expression. A previous study demonstrated that estrogen effected TGF- $\beta 1$ expression in mouse endometrium by stimulating its expression in the stroma cells and inhibiting its expression in glandular epithelium (27). Another study reported that E2 expression significantly increased in response to TGF- $\beta 1$ secretion in cultured dermal fibroblasts following wound healing (27). Certain studies reported that estrogen reduced TGF- $\beta$ expression in endometrial carcinoma; however, these studies were based on a different abnormal cell growth mechanism of endometrial cancer cells and hormone release $(28,29)$. The results of the present study demonstrated that TGF- $\beta$ may increase the expression of IDO in a dose-dependent manner, and that TGF- $\beta$ was highly expressed in chorionic villi and decidua tissues of normal pregnant women.

During pregnancy, ovaries induce placenta cell-mediated production of high concentrations of estrogen and progesterone. Abnormally low levels of estrogen and progesterone can lead to a miscarriage, while abnormally high levels may disturb the function of ovaries and cause cancer or early menopause. The mean cord serum concentration of $\mathrm{E} 2$ is $\sim 7.5 \mathrm{ng} / \mathrm{ml}$ (range, $4-13 \mathrm{ng} / \mathrm{ml}$ ) and the mean cord serum concentration of E3 is $0.3 \mu \mathrm{g} / \mathrm{ml}$ (range, $0.2-0.5 \mu \mathrm{g} / \mathrm{ml}$ ) during pregnancy (30). For our study, the $10 \mathrm{ng} / \mathrm{ml} \mathrm{E} 2$ and $1 \mu \mathrm{g} / \mathrm{ml} \mathrm{E} 3$ is more suitable for increased TGF- $\beta$ and IDO expression, one of the causes is by simulation of pregnancy women uterus micro-environment in vitro, for another possibility is about the toxicological effect of estrogen and progesterone added in cultured tissues. Since high concentrations of estrogen and high TGF- $\beta$ expression levels were simultaneously observed in chorionic villi and decidua tissues, it unlikely that estrogen downregulates TGF- $\beta$ expression. Fulvestrant functions as an antagonist of estrogen and is used to treat postmenopausal patients with hormone receptor-positive advanced breast cancer (31). The results of the current study showed that estrogen could upregulate TGF- $\beta$ expression in chorionic villi and decidua tissues cultured in medium containing E2 or E3. Furthermore, this effect was reversed by fulvestrant, an inhibitor of estrogen receptor.

The results of the present study demonstrated that IDO was expressed in chorionic villi and decidua tissues, and that TGF- $\beta$ may upregulate IDO expression in these tissues. Furthermore, the results indicated that estrogen during pregnancy may induce maternal-fetal tolerance by upregulation of IDO via TGF- $\beta$, E2 and E3. The current study had certain limitations. A wider range of E2 and E3 does will be necessary to confirm the colclusions. Furthermore, Pearson's correlation analysis of the association between the maternal E1, E2 and E3 levels in chorionic villi and decidua tissues and peripheral blood TGF- $\beta /$ IDO expression levels was not performed. A future study will explore the downstream and upstream signaling pathways of TGF- $\beta$, and other molecules that may be involved in estrogen signaling pathways, such as Smad 3 and Stat 3 . The protein expression levels of TGF- $\beta$ and IDO receptors, and the receptors of estrogen and progesterone should also be determined in future studies.

In conclusion, the current results indicated that there may be an association between estrogen and TGF- $\beta$ and IDO expression levels in chorionic villi and decidua tissues. Inhibition of estrogen signaling decreased TGF- $\beta$ and IDO expression levels, suggesting that estrogen may upregulate IDO expression via TGF- $\beta$. The current findings may be used in future clinical research to support the understanding of the molecular mechanism of maternal-fetal immunological tolerance. The current results may also be used for the development of effective treatment for autoimmune diseases, including transplant rejection and immune infertility $(32,33)$.

\section{Acknowledgements}

The authors thank Dr Fang Yu (Clinical Laboratory Center, Affiliated Hospital of Guizhou Medical University, Guizhou, China) for helpful suggestions regarding the experiments. 


\section{Funding}

This study was supported by the National Natural Science Foundation of China (grant no. 81360452).

\section{Availability of data and materials}

The data sets used and/or analyzed during the current study are available from the corresponding author on reasonable request.

\section{Authors' contributions}

JW, GH, SZ, ZC, ZX, LW and FS conceived and designed the study. JW and PL analyzed the data. JW, ZC and MY performed the experiments. YW, LY, YT, HZ and JW recruited patients, collected the chorionic villi and decidua samples, and analyzed patient information. JW and GH wrote the manuscript. SZ was responsible for the acquisition of funding. All authors agreed with manuscript results and conclusions and approved the final manuscript.

\section{Ethics approval and consent to participate}

The current study was conducted according to the principles expressed in the Declaration of Helsinki. The study was approved by the Ethics Committee of the Affiliated Hospital of Guizhou Medical University (Guizhou, China). All patients who have undergone voluntary termination of pregnancy provided written informed consent for the collection of samples and subsequent analysis.

\section{Patient consent for publication}

Not applicable.

\section{Competing interests}

The authors declare that they have no competing interests.

\section{References}

1. Trowsdale J and Betz AG: Mother's little helpers: Mechanisms of maternal-fetal tolerance. Nat Immunol 7: 241-246, 2006.

2. Tafuri A, Alferink J, Möller P, Hämmerling GJ and Arnold B: $\mathrm{T}$ cell awareness of paternal alloantigens during pregnancy. Science 270: 630-633, 1995.

3. Hogarth PJ: Immunological aspects of foeto-maternal relations in lower vertebrates. J Reprod Fertil Suppl 3 (Suppl 3): S15-S27, 1968.

4. Kaufmann P, Huppertz B and Frank HG: The fibrinoids of the human placenta: Origin, composition and functional relevance. Ann Anat 178: 485-501, 1996.

5. Xiong YH, Yuan Z and He L: Effects of estrogen on CD4(+) $\mathrm{CD} 25(+)$ regulatory $\mathrm{T}$ cell in peripheral blood during pregnancy. Asian Pac J Trop Med 6: 748-752, 2013.

6. Terness P, Bauer TM, Röse L, Dufter C, Watzlik A, Simon H and Opelz G: Inhibition of allogeneic T cell proliferation by indoleamine 2,3-dioxygenase-expressing dendritic cells: Mediation of suppression by tryptophan metabolites. J Exp Med 196: 447-457, 2002.

7. Mellor AL, Baban B, Chandler P, Marshall B, Jhaver K, Hansen A, Koni PA, Iwashima M and Munn DH: Cutting edge: Induced indoleamine 2,3 dioxygenase expression in dendritic cell subsets suppresses T cell clonal expansion. J Immunol 171: $1652-1655,2003$
8. Kudo Y, Boyd CA, Spyropoulou I, Redman CW, Takikawa O, Katsuki T, Hara T, Ohama K and Sargent IL: Indoleamine 2,3-dioxygenase: Distribution and function in the developing human placenta. J Reprod Immunol 61: 87-98, 2004.

9. Curti A, Trabanelli S, Salvestrini V, Baccarani M and Lemoli RM: The role of indoleamine 2,3-dioxygenase in the induction of immune tolerance: Focus on hematology. Blood 113: 2394-2401, 2009.

10. Ligam P, Manuelpillai U, Wallace EM and Walker D: Localisation of indoleamine 2,3-dioxygenase and kynurenine hydroxylase in the human placenta and decidua: Implications for role of the kynurenine pathway in pregnancy. Placenta 26: 498-504, 2006.

11. Liu W, Huang Y, Huang G, Zhou C, Zeng X, Zhao S, Wu L, Zhou H, Wu Q and Dai L: Relationship of SOCS3 and TGF- $\beta$ with IDO expression in early pregnancy chorionic villi and decidua. Exp Ther Med 14: 4817-4824, 2017.

12. Fallarino F, Grohmann U, Vacca C, Bianchi R, Orabona C, Spreca A, Fioretti MC and Puccetti P: T cell apoptosis by tryptophan catabolism. Cell Death Differ 9: 1069-1077, 2002.

13. Frumento G, Rotondo R, Tonetti M, Damonte G, Benatti U and Ferrara GB: Tryptophan-derived catabolites are responsible for inhibition of $\mathrm{T}$ and natural killer cell proliferation induced by indoleamine 2,3-dioxygenase. J Exp Med 196: 459-468, 2002.

14. Hönig A, Rieger L, Kapp M, Sütterlin M, Dietl J and Kämmerer U: Indoleamine 2,3-dioxygenase (IDO) expression in invasive extravillous trophoblast supports role of the enzyme for materno-fetal tolerance. J Reprod Immunol 61: 79-86, 2004.

15. Huang G, Zeng Y, Liang P, Zhou C, Zhao S, Huang X, Wu L and $\mathrm{He} \mathrm{X}$ : Indoleamine 2,3-dioxygenase (IDO) downregulates the cell surface expression of the CD 4 molecule. Int J Mol Sci 13: 10863-10879, 2012.

16. Biernacka A, Dobazewski $M$ and Frangogiannis NG: TGF- $\beta$ signaling in fibrosis. Growth Factor 29: 196-202, 2011.

17. Pallotta MT, Orabona C, Volpi C, Vacca C, Belladonna ML, Bianchi R, Servillo G, Brunacci C, Calvitti M, Bicciato S, et al: Indoleamine 2,3-dioxygenase is a signaling protein in long-term tolerance by dendritic cells. Nat Immunol 12: 870-878, 2011.

18. ESHRE Guideline Group on RPL, Bender Atik R, Christiansen OB, Elson J, Kolte AM, Lewis S, Middeldorp S, Nelen W, Peramo B, Quenby S, et al: ESHRE guideline: Recurrent pregnancy loss. Hum Reprod Open 2018: hoy004, 2018.

19. Kudo Y: The role of placental indoleamine 2,3-dioxygenase in human pregnancy. Obstet Gynecol Sci 56: 209-216, 2013.

20. Mei J, Li MQ, Ding D, Li DJ, Jin LP, Hu WG and Zhu XY: Indoleamine 2,3-dioxygenase-1 (IDO1) enhances survival and invasiveness of endometrial stromal cells via the activation of JNK signaling pathway. Int J Clin Exp Pathol 6: 431-444, 2013.

21. Honig A, Rieger L, Dietl J and Kämmerer U: Mechanisms regulating the expression of indoleamine 2,3-dioxygenase during decidualization of human endometrium. Hum Reprod 19: 2683-2684, 2004.

22. Zhu WH, Lu CZ, Huang YM, Link H and Xiao BG: A putative mechanism on remission of multiple sclerosis during pregnancy: Estrogen-induced indoleamine 2,3-dioxygenase by dendritic cells. Mult Scler 13: 33-40, 2007.

23. Troisi R, Potischman N, Johnson CN, Roberts JM, Lykins D, Harger G, Markovic N, Siiteri P and Hoover RN: Estrogen and androgen concentrations are not lower in the umbilical cord serum of pre-eclamptic pregnancies. Cancer Epidemiol Biomarkers Prev 12 (11 Pt 1): 1268-1270, 2003.

24. Matalka KZ: The effect of estradiol, but not progesterone, on the production of cytokines in stimulated whole blood, is concentration-dependent. Neuro Endocrinol Lett 24: 185-191, 2003.

25. Xuan YH, Choi YL, Shin YK, Ahn GH, Kim KH, Kim WJ Lee $\mathrm{HC}$ and $\mathrm{Kim} \mathrm{SH}$ : Expression of TGF-beta signaling proteins in normal placenta and gestational trophoblastic disease. Histol Histopathol 22: 227-234, 2007.

26. Jones RL, Stoikos C, Findlay JK and Salamonsen LA: TGF-beta superfamily expression and actions in the endometrium and placenta. Reproduction 132: 217-232, 2006.

27. Stevenson S, Nelson LD, Sharpe DT and Thornton MJ: 17beta-estradiol regulates the secretion of TGF-beta by cultured human dermal fibroblasts. J Biomater Sci Polym Ed 19: 1097-1109, 2008

28. Lecanda J, Parekh TV, Gama P, Lin K, Liarski V, Uretsky S, Mittal K and Gold LI: Transforming growth factor-beta, estrogen, and progesterone converge on the regulation of $\mathrm{p} 27 \mathrm{Kip} 1$ in the normal and malignant endometrium. Cancer Res 67: 1007-1018, 2007. 
29. Ito L, Hanyu A, Wayama M, Goto N, Katsuno Y, Kawasaki S, Nakajima Y, Kajiro M, Komatsu Y, Fujimura A, et al: Estrogen inhibits transforming growth factor beta signaling by promoting Smad2/3 degradation. J Biol Chem 285: 14747-14755, 2010.

30. Noyola-Martinez N, Halhali A and Barrera D: Steroid hormones and pregnancy. Gynecol Endocrinol 35: 376-384, 2019.

31. Wang J, Xu B, Wang W, Zhai X and Chen X: Efficacy and safety of fulvestrant in postmenopausal patients with hormone receptor-positive advanced breast cancer: A systematic literature review and meta-analysis. Breast Cancer Res Treat 171: 533-544, 2018.
32. Gao J, Deng F and Jia W: Inhibition of indoleamine 2,3-dioxygenase enhances the therapeutic efficacy of immunogenic chemotherapeutics in breast cancer. J Breast Cancer 22: 196-209, 2019.

33. Nishi M, Yoshikawa K, Higashijima J, Tokunaga T, Kashihara H, Takasu C, Ishikawa D, Wada Y and Shimada M: The impact of indoleamine 2,3-dioxygenase (IDO) expression on Stage III gastric cancer. Anticancer Res 38: 3387-3392, 2018. 